Check for updates

Cite this: Mater. Adv., 2022, 3, 1055

Received 16th August 2021, Accepted 26th November 2021

DOI: $10.1039 / \mathrm{d} 1 \mathrm{ma} 00729 \mathrm{~g}$

rsc.li/materials-advances

\title{
Effect of PEDOT:PSS on the performance of solution-processed blue phosphorescent organic light-emitting diodes with an exciplex host $\uparrow$
}

\begin{abstract}
Jaber Saghaei, ${ }^{a}$ Manikandan Koodalingam, (D) a Paul L. Burn, (D) *a Ian R. Gentle, (D) ${ }^{a}$ Almantas Pivrikas ${ }^{b}$ and Paul E. Shaw (iD ${ }^{a}$

In this study, efficient solution-processed organic light-emitting diodes (OLEDs) based on a light-emitting layer composed of a blue emissive phosphorescent dendrimer and exciplex host were investigated. Employing poly(styrene sulfonic acid) doped poly(ethylenedioxythiophene):poly(styrenesulfonate) ( $m$-PEDOT:PSS) as the hole injection layer resulted in devices with external quantum efficiencies (EQEs) over $20 \%$ for luminances of up to $100 \mathrm{~cd} \mathrm{~m}^{-2}$. A feature of these devices was a relatively slow electroluminescence turn-on for the initial voltage scan, which was absent when $m$-PEDOT:PSS was replaced with molybdenum oxide as the hole injection layer. The initial turn-on rate was found to decrease with increasing PSSH content, with the results suggesting that proton migration from ( $m$-)PEDOT:PSS is the cause of the change in the device performance. The overall device performance was found to be scan dependent, with sequential voltage scans leading to a decrease in EQE, which is ascribed at least in part to electromer formation. We also demonstrate solution-processed OLEDs with the same exciplex host and bis[2-(4,6-difluorophenyl)pyridinato- $\left.C_{2}, N\right]$ (picolinato)iridium(III) (FIrpic) as the emitter, that have maximum EQE and power efficiencies of $17.0 \%$ and $25.3 \mathrm{~lm} \mathrm{~W}^{-1}$, respectively.
\end{abstract}

\section{Introduction}

Films of exciplex-forming materials have given rise to organic light-emitting diodes (OLEDs) with good efficiencies either as emissive layers or as hosts for phosphorescent, thermally activated delayed fluorescence (TADF), or fluorescent emitters. ${ }^{1-9}$ A reported feature of bulk exciplex films when used as a host for guest emitters is their ambipolarity, ${ }^{10}$ which arises from the fact that they are composed of a blend of low ionisation potential (donor) and high electron affinity (acceptor) materials. The blend of the two materials has been observed to reduce both the operating voltage and efficiency roll-off, which in the case of the latter has been attributed to the placement and broadening of the recombination zone in the emissive layer. A potential advantage of bulk exciplex films, and their covalently linked analogues (TADF materials), is that they can be designed to have sufficiently high singlet and triplet energies with small singlet and triplet energy gaps $\left(\Delta E_{\mathrm{ST}}\right)$ to prevent energy back transfer

\footnotetext{
${ }^{a}$ Centre for Organic Photonics \& Electronics (COPE), School of Chemistry and Molecular Biosciences, The University of Queensland, Brisbane, Queensland 4072, Australia.E-mail: p.burn2@uq.edu.au

${ }^{b}$ School of Engineering and Information Technology, Murdoch University, Perth, Western Australia, 6150, Australia

$\dagger$ Electronic supplementary information (ESI) available. See DOI: 10.1039/ d1ma00729g
}

from the emissive guest. An advantage of exciplex blends over TADF materials as hosts is that they can be formed by simply blending two materials, thus enabling many different materials combinations and ratios to be investigated. ${ }^{11}$ The majority of exciplex blend host studies have focussed on films that are deposited by vacuum evaporation with there being few reports of solution processed exciplex host-based OLEDs. ${ }^{12,13}$

While the creation of exciplex host blends for green and red guest emitters is relatively straightforward, it is more difficult to create donor-acceptor combinations that form suitable hosts for blue emissive materials,${ }^{14}$ and in particular, solutionprocessed blue phosphorescent emitters. The emission energy of the exciplex host is governed by the ionisation potential of the donor and the electron affinity of the acceptor and hence there needs to be a sufficiently large energy offset such that neither component of the exciplex host nor the formed exciplex quench the triplet state of the blue emitter. In the context of solution processed blue-phosphorescent emitters, there have been a number of reports of exciplex hosts composed of $4,4^{\prime}, 4^{\prime \prime}$ tris(carbazol-9-yl)triphenylamine (TCTA) (donor) (and derivatives) and phosphine oxide-based acceptors with bis[2-(4,6difluorophenyl)pyridinato- $\left.C_{2}, N\right]$ (picolinato)iridium (III) (FIrpic) as the emitter. ${ }^{15-19}$ In fact, most reports describing solutionprocessed bulk exciplex hosts for blue emissive guests include the use of phosphine oxide derivatives as the acceptor in the 
blend, which is due to their relatively small electron affinities and high triplet energies. ${ }^{15}$ The best performing of these thus far had a device architecture of ITO/PEDOT:PSS/Ph-O-TCTA:PhPO:FIrpic/ $\mathrm{TPBI} / \mathrm{Cs}_{2} \mathrm{CO}_{3} / \mathrm{Al}$ [PEDOT:PSS = poly(ethylenedioxythiophene): poly(styrenesulfonate), $\mathrm{Ph}-\mathrm{O}-\mathrm{TCTA}=\mathrm{a}$ tris-TCTA based macromolecule, $\mathrm{PhPO}=\operatorname{tris}[4$-(diphenylphosphoryl)phenyl $]$ benzene, $\mathrm{TPBI}=$ 2,2' $2^{\prime \prime}$-[1,3,5-benzinetriyl]-tris[1-phenyl-1- $H$-benzimidazole], $\mathrm{Cs}_{2} \mathrm{CO}_{3}=$ caesium carbonate, $\mathrm{Al}=$ aluminium] giving an external quantum efficiency of $16.5 \%$, and power (PE) and current (CE) efficiencies of $20.6 \mathrm{~lm} \mathrm{~W}{ }^{-1}$ and $33.6 \mathrm{~cd} \mathrm{~A}^{-1}$, respectively. ${ }^{19}$ However, one of the issues of developing solution-processed blue phosphorescentexciplex host films is that many of the available materials have been developed for evaporative processing and do not always form good quality films from solution. For example, solution processed films of FIrpic generally contain aggregates. ${ }^{20-23}$ In early work on solution processed phosphorescent OLEDs it was shown that lightemitting dendrimers could form good quality films when blended with host materials that had poor solubility and propensity to aggregate when deposited from solution. ${ }^{24}$ In this paper we show that a blue phosphorescent light-emitting dendrimer, $\operatorname{Ir}(\mathrm{DTri})_{3}$, blended with a TCTA:POPH exciplex host (see Fig. 1 for structures) can be solution processed to form films of good quality. The choice of a TCTA:POPH blend as the exciplex host was based on the fact that it had been successfully used for FIrpic and that Ir(DTri) $)_{3}$ was also a sky blue emitter. Furthermore, we report and discuss the photophysical, electronic and device properties of the blend emissive films and compare the device performance with films using FIrpic as the emissive material.

\section{Results and discussion}

\section{Photophysical and electrical properties}

We first investigated the photophysical properties of the neat exciplex films and those blended with 5 -fac-tris $\left[4^{\prime \prime}\right.$-( $t$-butyl)$5^{\prime}-\{4$-[t-butyl]phenyl $\}-4^{\prime}$-methyl-(1,1': $3^{\prime}, 1^{\prime \prime}$-terphenyl)-3-yl]-1methyl-3-propyl-1H-1,2,4-triazolyl]iridium(III) [Ir(DTri) $\left.{ }_{3}\right]$. A 1:1 molar ratio of the TCTA and [5-terphenyl-1,3-phenylene] bis[diphenylphosphine oxide] (POPH) was chosen so that in principle every donor had its own acceptor. Films were prepared from dichloromethane solutions to ensure that both the TCTA and POPH were dissolved. The film absorption spectrum of the 1:1 molar ratio of TCTA and POPH was found to be a linear combination of the individual TCTA and POPH absorption spectra (Fig. S1, ESI $\dagger$ ). Therefore, to a first approximation no

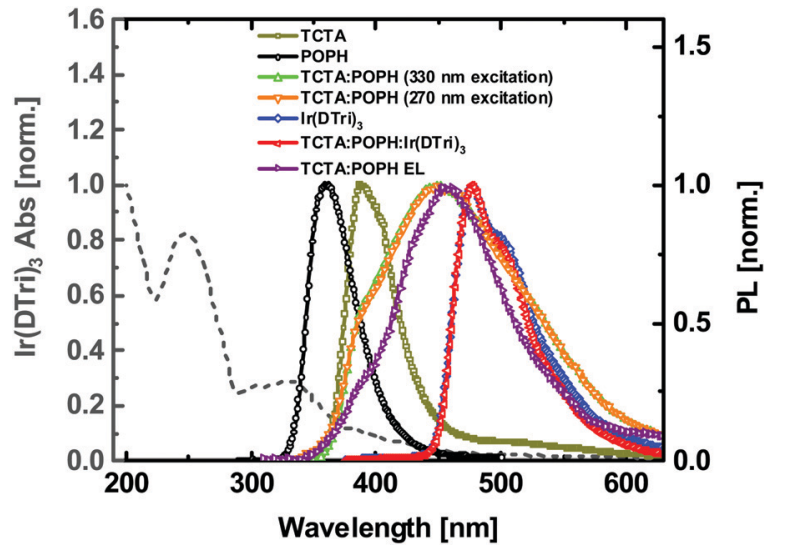

Fig. 2 Absorption spectrum of $\operatorname{Ir}(\mathrm{DT}$ ri) 3 and $\mathrm{PL}$ spectra of the individual components and blends (1:1 molar ratio TCTA:POPH and $20 \mathrm{wt} \% \operatorname{Ir}(\mathrm{DTri})_{3}$ in TCTA:POPH at a $1: 1$ molar ratio $-\lambda_{\text {exc }}=330 \mathrm{~nm}$ and $\lambda_{\text {exc }}(\mathrm{POPH})=$ $270 \mathrm{~nm}$ ). In terms of calculating the weight percent (wt\%) of $\operatorname{Ir}(\mathrm{DTri})_{3}$ in the film, the TCTA and POPH are taken as a combined weight. That is, the film with 20 wt\% $\operatorname{Ir}(\mathrm{DTri})_{3}$ has 80 wt\% of the $1: 1$ molar ratio of TCTA and POPH. Note the neat TCTA PL spectrum has a broad emission out to around $600 \mathrm{~nm}$, which arises from aggregate/excimer emission.

ground state interactions (aggregation or charge transfer state formation) were observed between the TCTA and POPH in blend. $^{25,26}$ The PL spectra of TCTA, POPH, the 1:1 TCTA:POPH blend and the blend containing $\operatorname{Ir}(\mathrm{DTri})_{3}$ are shown in Fig. 2. POPH has a featureless PL emission that is at a shorter wavelength than TCTA, which is consistent with the higher energy absorption onset. The 1:1 TCTA:POPH blend film had a broad PL feature associated with the exciplex emission, with a shoulder clearly visible on the high energy side. The broad and featureless PL emission of an exciplex is due to the existence of various emissive species in the blend. ${ }^{10}$ The shoulder at shorter wavelengths of around $385 \mathrm{~nm}$ indicates there was emission from TCTA as well as the exciplex, which was confirmed by exciting the film at $330 \mathrm{~nm}$ where the TCTA absorbs but POPH does not (see Fig. S1, ESI $\dagger$ ). However, exciting the film at $270 \mathrm{~nm}$ excites both the POPH and TCTA (which are in a 1:1 molar ratio) and it can be seen in Fig. 2 that in addition to the exciplex and TCTA emission there was small component of the emission at $355 \mathrm{~nm}$, which is consistent with POPH emission. Thus, in spite of the donor and acceptor materials being in a 1:1 molar ratio, not all the emission is exciplex-based, which is suggestive of a degree of phase separation in the spin-coated film. ${ }^{27}$

The PL emission of the $20 \mathrm{wt} \% \operatorname{Ir}(\mathrm{DTri})_{3}$ in a 1:1 molar ratio TCTA:POPH film is also shown in Fig. 2. At first glance it

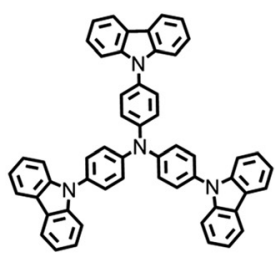

TCTA

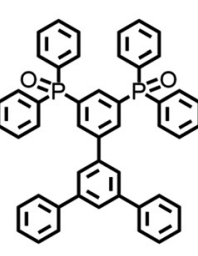

$\mathrm{POPH}$

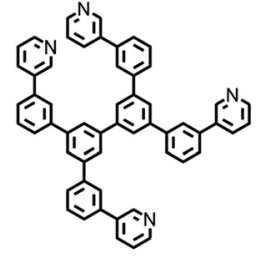

BP4mPy

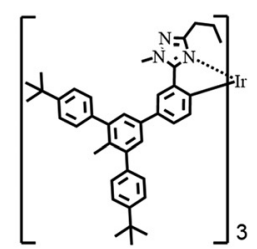

$\operatorname{Ir}(\mathrm{DTri})_{3}$

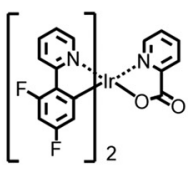

FIrpic

Fig. 1 Structures of TCTA, POPH, Ir(DTri) 3 , Flrpic, and the electron transport/hole blocking BP4mPy used in the bilayer devices. 
appears that at an excitation wavelength of $330 \mathrm{~nm}$ only emission from $\operatorname{Ir}(\mathrm{DTri})_{3}$ is observed. Indeed, Fig. S2a (ESI $\dagger$ ) shows that the PL spectrum is independent of the excitation wavelength (250-350 nm). However, plotting the PL spectra on a logarithmic scale, Fig. S2b (ESI $\dagger$ ), it can be seen that even up to a concentration of $30 \mathrm{wt} \% \operatorname{Ir}(\mathrm{DTri})_{3}$ there is still a small component of host emission.

The PL quantum yields (PLQYs) of films with different dendrimer concentrations are summarised in Fig. 3. The exciplex host films (with no guest) had a low PLQY of $3 \pm 1 \%$. The PLQY was found to reach a maximum of $67 \pm 6 \%$ for a dendrimer concentration of $20 \mathrm{wt} \%$ with the neat dendrimer film having a PLQY of $16 \pm 2 \%$. The solution PLQY of the dendrimer is $73 \pm$ $8 \%$, which was close to that of the $20 \mathrm{wt} \%$ dendrimer blend film, indicating that the dendrimers are not strongly interacting with each other in the exciplex host at that concentration. ${ }^{28-30}$

In the final part of the study on the PL properties we measured the PL decays of the exciplex TCTA:POPH blend and $\operatorname{Ir}(\mathrm{DTri})_{3}$ films, and films containing different concentrations of $\operatorname{Ir}(\mathrm{DTri})_{3}$ (Fig. $3 \mathrm{~b}$, with the lifetime fitting
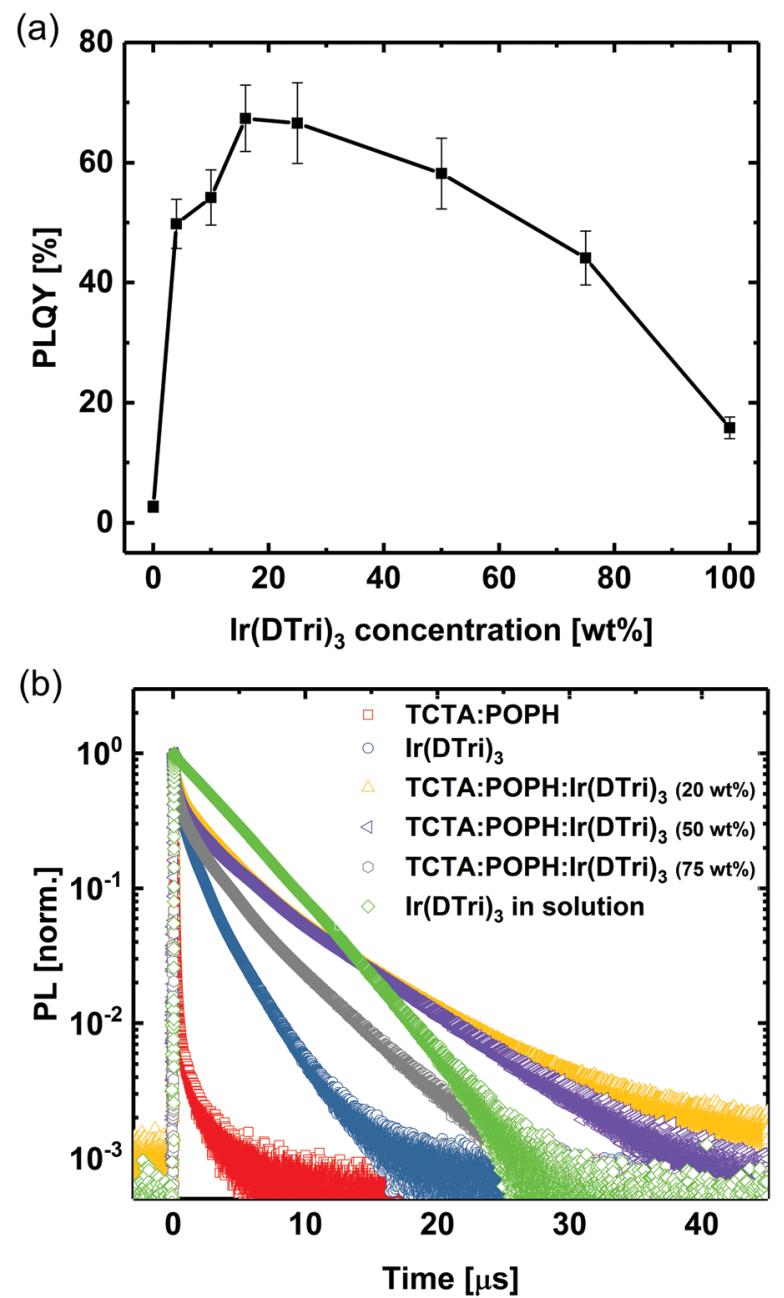

Fig. 3 (a) PLQYs of films with different dendrimer concentrations. (b) TRPL decays of Ir(DTri) ${ }_{3}$ in solution, films of the exciplex host or dendrimer, and exciplex films containing different concentrations of the dendrimer. parameters for the exciplex host, neat dendrimer and $20 \mathrm{wt} \%$ dendrimer blend summarised in Table S1, ESI $\dagger$ ). The PL decay of $\operatorname{Ir}(\mathrm{DTri})_{3}$ in solution is also shown for comparison. In solution, $\operatorname{Ir}(\mathrm{DTri})_{3}$ had a mono-exponential decay with a lifetime of $4.1 \mu \mathrm{s}$, which is consistent with an absence of interchromophore interactions. The 1:1 molar ratio TCTA:POPH blend film was found to have a multi-exponential decay with a lifetime longer than that of individual films of TCTA and POPH, which again confirms exciplex emission from the host film. The neat $\operatorname{Ir}(\text { DTri })_{3}$ also had a multi-exponential decay, with the largest component having a lifetime shorter than that measured in solution. These characteristics are consistent with there being intermolecular interchromophore interactions that lead to the quenching of the luminescence in the neat $\operatorname{Ir}(\mathrm{DTri})_{3}$ film. The film PL lifetimes were found to decrease with increasing $\operatorname{Ir}(\mathrm{DTri})_{3}$ concentration, with the neat film of $\operatorname{Ir}(\mathrm{DTri})_{3}$ having the shortest. These results are consistent with the PLQY measurements and an increase in intermolecular interchromophore interactions between the emissive $\operatorname{Ir}(\mathrm{DTri})_{3}$ macromolecules with increasing guest concentration in the mixed exciplex host.

Prior to fabricating and testing OLEDs containing the emissive layer materials, we measured their hole and electron mobilities using metal-insulator-semiconductor charge extraction by linearly increasing voltage (MIS-CELIV) and photo-MIS-CELIV, respectively (Fig. S3 shows the transients, ESI $\dagger$ ). The neat film of $\operatorname{Ir}(\mathrm{DTri})_{3}$ had a hole mobility of $(9.6 \pm$ $0.7) \times 10^{-5} \mathrm{~cm}^{2} \mathrm{~V}^{-1} \mathrm{~s}^{-1}$ and the exciplex blend film had hole and electron mobilities of $(1.1 \pm 0.3) \times 10^{-6}$ and $(8.5 \pm 1.3) \times$ $10^{-7} \mathrm{~cm}^{2} \mathrm{~V}^{-1} \mathrm{~s}^{-1}$, respectively. The similarity of the electron and hole mobilities of the TCTA:POPH blend film demonstrates the ambipolar charge transport characteristics and its suitability as a host. The electron $[(8.0 \pm 1.2) \times$ $\left.10^{-8} \mathrm{~cm}^{2} \mathrm{~V}^{-1} \mathrm{~s}^{-1}\right]$ and hole $\left[(4.9 \pm 0.8) \times 10^{-7} \mathrm{~cm}^{2} \mathrm{~V}^{-1} \mathrm{~s}^{-1}\right]$ mobilities of the emissive layer containing $20 \mathrm{wt} \%$ of $\operatorname{Ir}(\mathrm{DTri})_{3}$ were lower than those of the TCTA:POPH blend, which is consistent with the $\operatorname{Ir}(\mathrm{DTri})_{3}$ trapping the charges. ${ }^{31,32}$

\section{Exciplex organic light-emitting diodes}

We fabricated OLEDs with the structure ITO/PEDOT:PSS/ (1:1)TCTA:POPH:Ir(DTri) $)_{3} / \mathrm{BP} 4 \mathrm{mPy} / \mathrm{LiF} / \mathrm{Al}\left[\mathrm{BP} 4 \mathrm{mPy}=3,3^{\prime}, 5,5^{\prime}-\right.$ tetra[(m-pyridyl)-phen-3-yl $]$ biphenyl, $\mathrm{LiF}=$ lithium fluoride $]$ with different wt\% of $\operatorname{Ir}(\mathrm{DTri})_{3}$ in the TCTA:POPH (1:1 molar ratio) host with the results shown in Fig. 4 and Table S2 (ESI $\dagger$ ) summarising the key device performance parameters. The highest external quantum efficiency (EQE) was observed for the devices containing emissive layers with $20 \mathrm{wt} \%$ of the $\operatorname{Ir}(\mathrm{DTri})_{3}$, which corresponded to the blend ratio with the highest PLQY (Fig. 3a). For each blend ratio the EQE was found to generally increase with luminance $(L)$ indicating unbalanced charge injection and transport at low luminance. ${ }^{33,34}$ That being said, at a luminance of $130 \mathrm{~cd} \mathrm{~m}^{-2}$ the EQE of $12.1 \%$ for the device with $20 \mathrm{wt} \% \operatorname{Ir}(\mathrm{DTri})_{3}$, was close to the theoretical maximum of $13.5 \%$ based on a film PLQY of $67 \pm 6 \%$ and the standard outcoupling of around $20 \%$ for a bottom emitting device. 

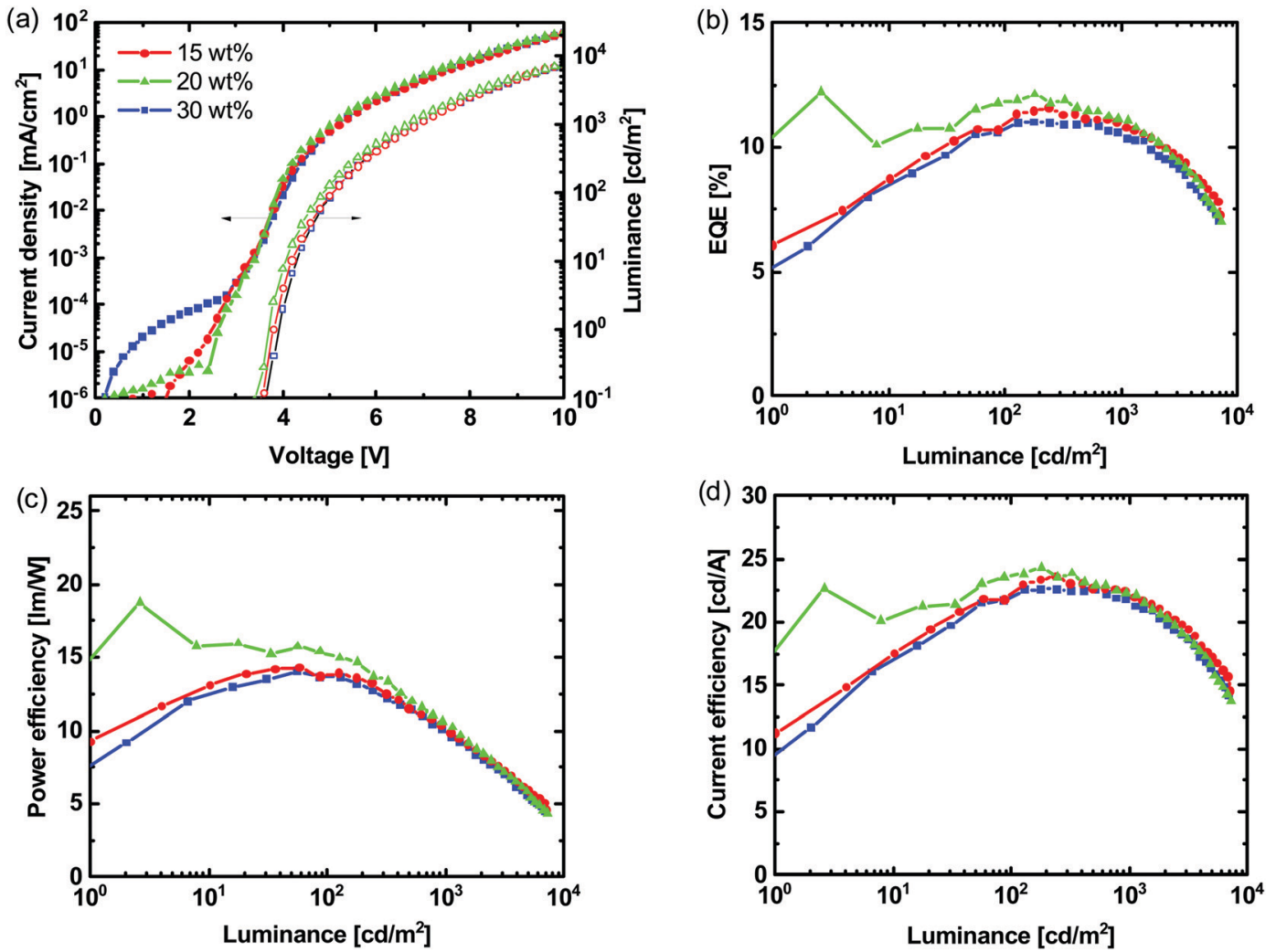

Fig. 4 (a) $J-V-L$, (b) EQE $-L$, (c) PE $-L$ and (d) $C E-L$ of OLEDs with the structure of ITO/PEDOT:PSS/TCTA:POPH:Ir(DTri) $3 / B P 4 m P y / L i F / A l$ with different $\operatorname{Ir}(\mathrm{DTri})_{3} \mathrm{wt} \%$ and a TCTA:POPH molar ratio of $1: 1$.

It has been reported that adding poly(4-styrenesulfonic acid) (PSSH) to PEDOT:PSS ( $m$-PEDOT:PSS) can increase the work function from $5.04 \mathrm{eV}$ to $5.59 \mathrm{eV}$ and improve hole injection. ${ }^{35}$ We therefore used $m$-PEDOT:PSS in place of PEDOT:PSS in the devices with $20 \mathrm{wt} \%$ of $\operatorname{Ir}(\mathrm{DTri})_{3}$ in the emissive layer with the results shown in Fig. 5 and the OLED performance characteristics summarised in Table S2 (ESI $\dagger$ ). Addition of the PSSH to PEDOT:PSS led to a dramatic difference in the EQE at low luminance for the first voltage scan, with the EQE reaching more than $20 \%$ at a luminance of up to around $20 \mathrm{~cd} \mathrm{~m}^{-2}$. This performance was repeatable on multiple pixels (see Table S2, ESI $\dagger$ ). However, at luminances of $\geq 100 \mathrm{~cd} \mathrm{~m}^{-2}$ the EQE for the $m$-PEDOT:PSS containing OLED was similar to that of devices that used pristine PEDOT:PSS ( $c f$. Fig. S4 and S5, ESI $\dagger$ ). To determine whether the high initial EQE was dependent on the trap density arising from the emitter concentration we also prepared a device with a smaller $\operatorname{Ir}(\mathrm{DTri})_{3}$ component. However, a high initial EQE was still observed when the $\operatorname{Ir}(\mathrm{DTri})_{3}$ concentration in the emissive layer was reduced to $2 \mathrm{wt} \%$ (Fig. S4, ESI $\dagger$ ). It should be noted that even though a high EQE was observed on the first scan, the PLQY values for all the emissive layers were less than $70 \%$. To determine whether this phenomenon was due to the $\operatorname{Ir}(\mathrm{DTri})_{3}$ emitter being dendrimeric we also prepared devices with the same configuration but with $10 \mathrm{wt} \%$ of FIrpic as the emissive material (the known optimum guest ratio). We found a similar effect with the maximum EQE and $\mathrm{PE}$ reaching to $17.0 \%$ and
$25.3 \mathrm{~lm} \mathrm{~W}^{-1}$, respectively, for the first scan, which is the highest reported thus far for solution processed exciplex OLEDs containing FIrpic (Fig. S5, ESI $\dagger$ ). As with the $\operatorname{Ir}(\mathrm{DTri})_{3}$ containing devices, at higher luminance the performance of the OLEDs containing either PEDOT:PSS or $m$-PEDOT:PSS were similar (Fig. S5, ESI $\dagger$ ).

At first sight the results of our OLEDs with the $m$-PEDOT:PSS seem to confirm the general improvement in performance previously reported. However, when we undertook several voltage scans, we found that the subsequent EQEs were lower (decreasing after the first scan before becoming relatively stable) than that measured on the first scan (note this effect was not highlighted in the published work). ${ }^{35}$ It is clear from the data in Fig. 6 that the first and subsequent voltage scans have different electrical and optical characteristics. A further observation we noted is that when the pixel was turned on and held at $4 \mathrm{~V}$ there was a delay in reaching uniform emission for devices composed of hole injection layers of either PEDOT:PSS or $m$-PEDOT:PSS (see Fig. 7), with the latter having a significantly slower turn-on. However, when the same pixel was turned off and then back on at $4.0 \mathrm{~V}$ there was no delay in illumination and the pixel had instant uniform emission.

The question therefore arises as to what are the origins of both the slow turn on and high EQEs for the first voltage scan. A high EQE in the first voltage scan could arise from one of the charge carriers filling traps in the emissive layer leading to a higher internal electric field that enhances the injection of the 

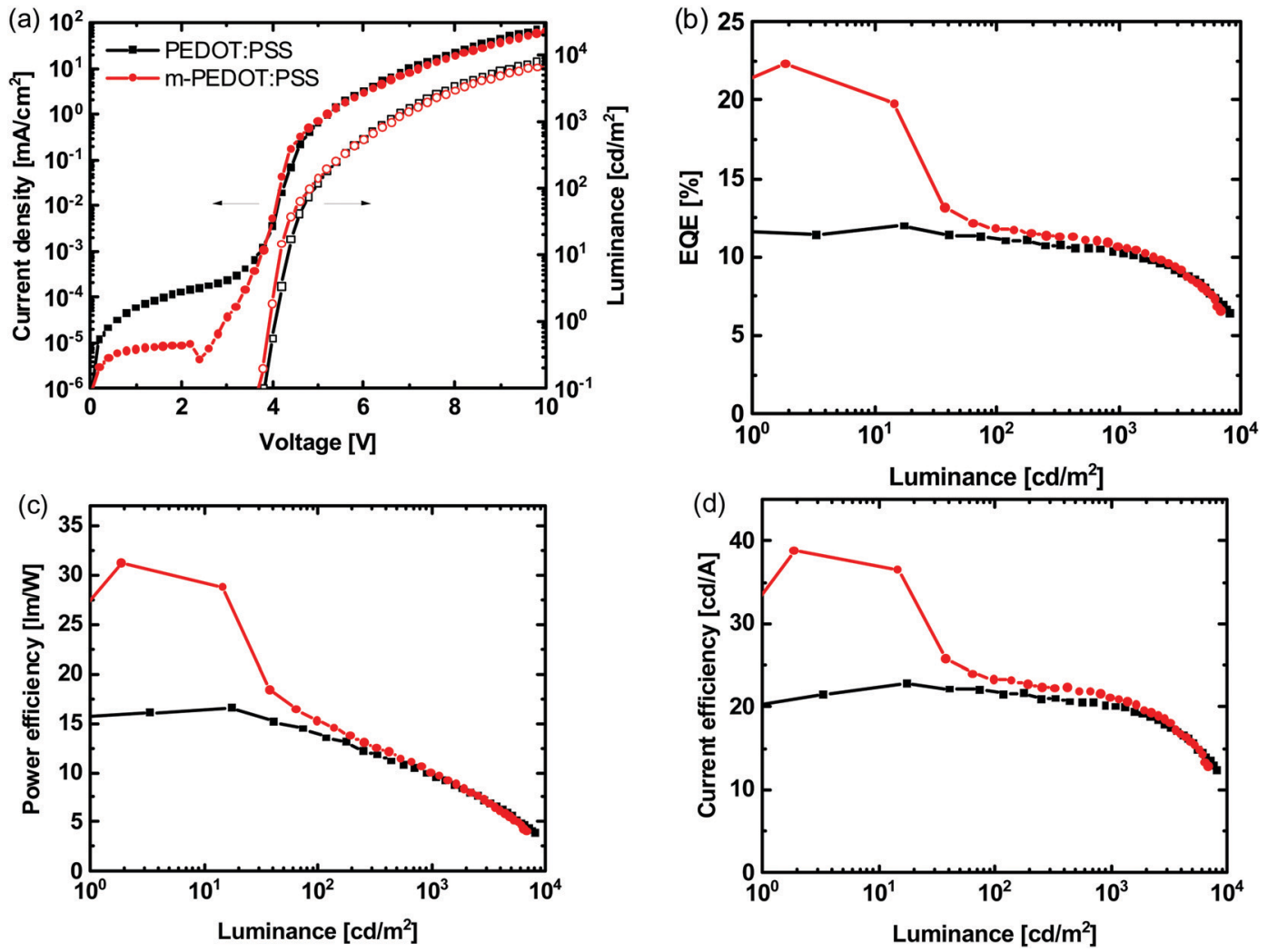

Fig. 5 (a) $J-V-L$, (b) EQE-L, (c) PE-L and (d) CE-L of OLEDs with PEDOT:PSS or $m$-PEDOT:PSS as the hole injection layer and (1:1) TCTA:POPH:(20 $w t \%)$ Ir(DTri) ${ }_{3}$ as the emissive layer.

second carrier at low voltage. In subsequent scans, the charge traps would remain filled and thus the internal electric field would be reduced. Such a situation could be affected by the distribution of the components in the emissive layer. For example, vertical phase separation of the components could lead to a different trap and electric field profile compared to the case where the materials are evenly distributed throughout the film. To check whether the components in the emissive layer were uniformly distributed we undertook depth profiling X-ray Photoelectron Spectroscopy measurements on a glass/ $m$-PEDOT:PSS/TCTA:POPH:(20 wt\%)Ir(DTri $)_{3} \quad$ film stack (Fig. S6, ESI $\dagger$ ). We found that based on the atomic percentages the ratio of the TCTA, POPH and $\operatorname{Ir}(\mathrm{DTri})_{3}$ was as expected from the ratio of the materials in the processing solution (Fig. S7a, ESI $\dagger$ ). In addition, there was no evidence of vertical separation of any of the components (Fig. S7b, ESI $\dagger$ ). This is in contrast to the reported accumulation of FIrpic at the PEDOT:PSS/EML interface $^{36}$ and is evidence of the ability of the dendrimeric $\operatorname{Ir}(\mathrm{DTri})_{3}$ to provide the processability needed to form good quality uniform thin films.

To test whether the slow turn-on (see Fig. 7) arises from trapped charges we held a device after a positive voltage scan at a negative bias of $-5 \mathrm{~V}$ for 10 minutes to attempt to depopulate the trap states and potentially restore the device to its original state. However, we found that there was no difference in the performance during the second positive voltage scan (Fig. S8, ESI $\dagger$ ). In addition, the fact that the time required for a pixel to reach uniform emission on the first scan is on the order of seconds suggests that an alternative mechanism to charge trapping is giving rise to the effect, e.g., proton migration from the $(m$-)PEDOT:PSS into the emissive layer. To confirm that the PEDOT:PSS is primarily responsible for the effect we prepared equivalent (1:1) TCTA:POPH:(20 wt\%)Ir(DTri $)_{3}$ devices with molybdenum oxide (MoOx) as the hole injection layer. While the devices had lower overall performance (see Fig. S9, ESI $\dagger$ ) there was no significant difference in the device characteristics between the first and subsequent voltage scans. Furthermore, the devices turned on instantaneously. Thus, differences in performance of the $(\mathrm{m}$-)PEDOT:PSS devices between voltage scans arise from the conducting polymer layer itself.

To determine whether the amount of PSSH added to the PEDOT:PSS had an effect on the performance of the devices we varied the PSSH concentration. We found that independent of the amount of PSSH added the first voltage scan always gave a high EQE at low luminance, which was higher than that of the devices with pristine PEDOT:PSS (Fig. S10, ESI $\dagger$ ). We also note that the delay in reaching uniform emission at an initial voltage of $4.0 \mathrm{~V}$ was dependent on the concentration of the PSSH in the $m$-PEDOT:PSS, with a greater amount of PSSH leading to a slower response. These results suggest that proton migration from ( $m$-)PEDOT:PSS into the emissive layer is primarily responsible for the first scan performance. To see whether we could block proton transfer we followed a previous report where a poly(9-vinylcarbazole) (PVK) layer was deposited onto the 

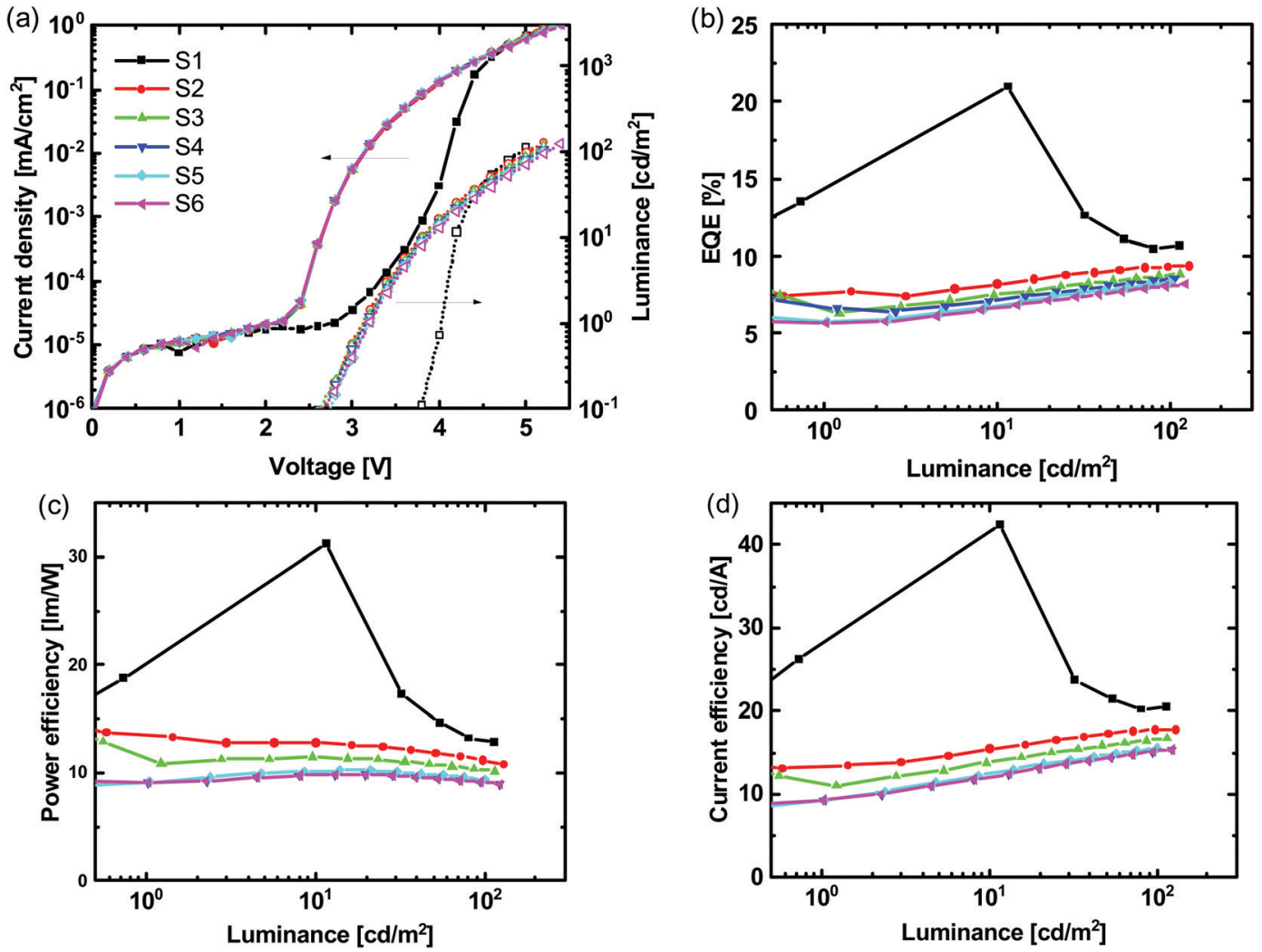

Fig. 6 (a) J-V-L, (b) EQE-L (c) PE-L and (d) CE-L of an OLED with the structure ITO/m-PEDOT:PSS/(1:1)TCTA:POPH:(20 wt\%)Ir(DTri) $3 /$ BP4mPy/LiF/Al for sequential voltage scans (S1-S6).

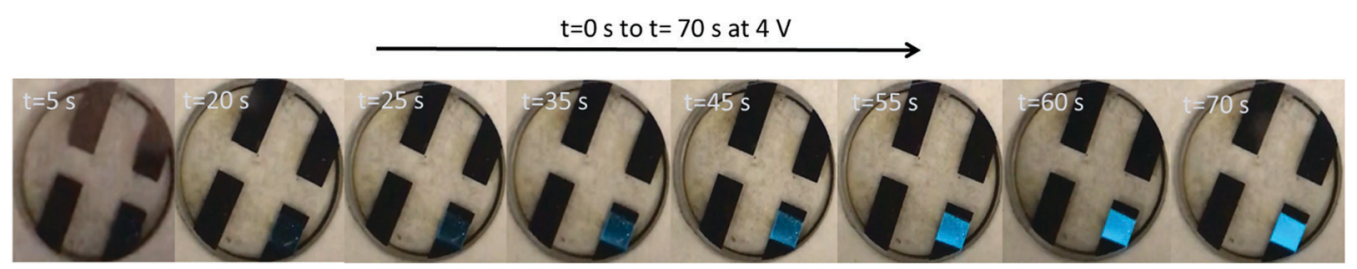

Fig. 7 Photos of an OLED composed of $m$-PEDOT:PSS and $\operatorname{Ir}(\mathrm{DTri})_{3}$ blended into the exciplex host held at $4.0 \mathrm{~V}$.

PEDOT:PSS layer before depositing the emissive film from solution. ${ }^{37}$ The driving voltage was found to increase for the device containing the PVK layer, which indicated that it was present despite it being thin $(<15 \mathrm{~nm})$. However, in our devices the PVK layer did not have a significant effect and a higher EQE was still observed for the first scan (Fig. S11, ESI $\dagger$ ).

In addition to the electrical characteristics, we measured the electroluminescence (EL) spectra of the devices (Fig. 8). For the devices containing $20 \mathrm{wt} \% \operatorname{Ir}(\mathrm{DTri})_{3}$ there was a small peak at $640 \mathrm{~nm}$ (note the log scale) in addition to the blue emission from the dendrimer. The peak at $640 \mathrm{~nm}$ was found to increase in intensity with multiple voltage scans. Previous reports of exciplex EL from TCTA:POPH blends have assigned the long wavelength peak to an electromer, ${ }^{16}$ and interestingly, in our work we did not observe the peak for the devices that had FIrpic as the emitter nor those with a MoOx hole injection layer (Fig. S5d and S9d, ESI $\dagger$ ). We also observed the peak at
$640 \mathrm{~nm}$ when the emissive layer only contained TCTA and $\operatorname{Ir}(\mathrm{DTri})_{3}$ (Fig. S12, ESI $\dagger$ ), i.e., with no POPH, indicating the feature is not exciplex in origin and is consistent with a TCTA electromer. ${ }^{16}$ The formation of an electromer can provide an additional weakly radiative decay pathway, which can in part explain the observed reduction in device efficiency with increasing number of scans. The fact that the electromer emission was not observed for the devices that had MoOx as the hole injection layer suggests that the (m-)PEDOT:PSS plays a role in its formation.

Although it is difficult to elucidate the reason for the electromer formation, previous reports have shown that protons ${ }^{38,39}$ and even fragments of PSS $^{36}$ can diffuse into the emissive layer. It is therefore not unreasonable to assume that these components could lead to the chemical changes of materials in the emissive layer that could lead to electromer formation or degradation of the materials. It is important to 

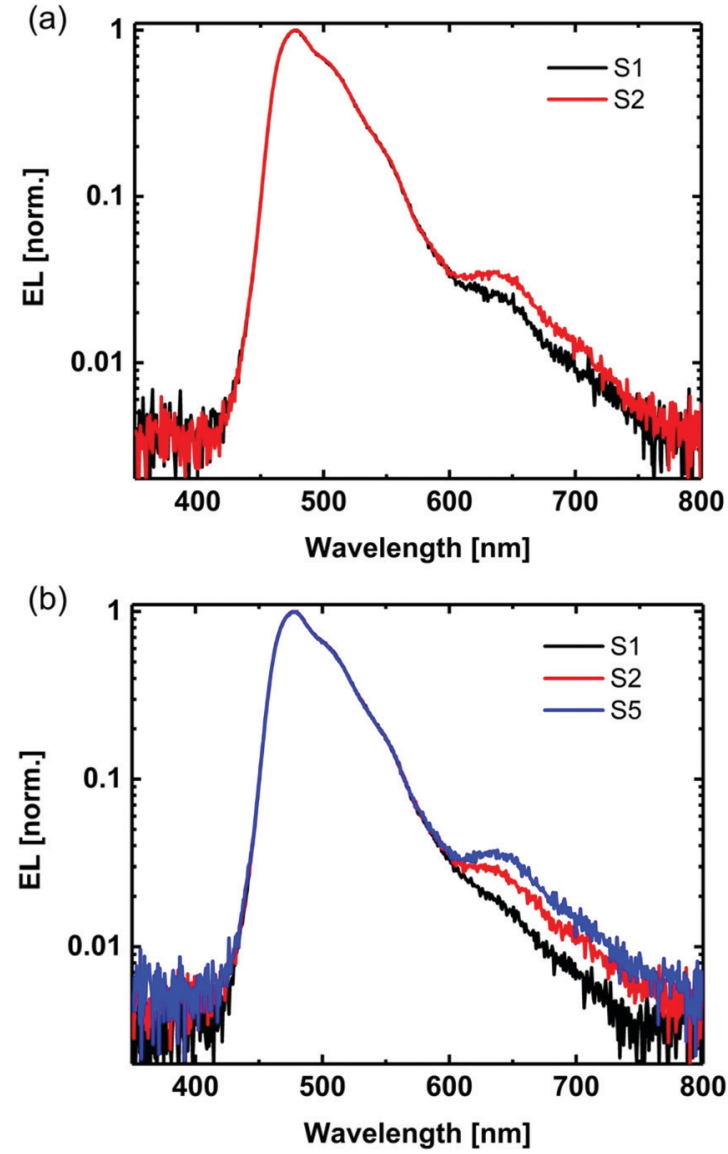

Fig. 8 EL spectra of OLEDs on (a) PEDOT:PSS and (b) $m$-PEDOT:PSS for different voltage scans. S represents "scan" and the scan number is shown.

note that electromer formation has been previously reported to be irreversible and will in part impact device stability. ${ }^{16,40}$

\section{Conclusion}

In summary, high efficiency blue dendrimer OLEDs based on an exciplex host were demonstrated, with maximum EQEs exceeding $20 \%$ at light intensities up to around $20 \mathrm{~cd} \mathrm{~m}^{-2}$. The maximum external quantum efficiency was notably more than the theoretical estimate based on the film PLQY (which was $67 \pm 6 \%$ ) and standard outcoupling of $20 \%$ for a bottom emitting device. However, the very high efficiency was only observed for the first voltage scan with subsequent voltage ramps giving a lower efficiency than the first. A feature of the devices was that there was a delay in the pixels achieving uniform emission when first measured. For subsequent measurements uniform emission was promptly observed above the turn-on voltage. Furthermore, it was found that a weakly emissive electromer formed during multiple voltage scans, which might in part explain the efficiency loss relative to the first scan. The changes in performance were not found when MoOx was used as the hole injection layer and hence we conclude that the PEDOT:PSS, particularly when doped with additional PSS, was the cause of the unusual device characteristics. Hence, we believe it is important that reports concerning OLEDs include data for higher scan numbers in addition to the first scan, particularly when ( $m$-)PEDOT:PSS is used as the hole injection layer.

\section{Experimental section}

\section{Material information}

Poly(ethylenedioxythiophene):poly(styrenesulfonate) (PEDOT:PSS aqueous solution - Clevios $\mathrm{Al} 4083 \mathrm{Ltd}$ ) was purchased from Ossila Ltd, 4,4',4"-tris[carbazol-9-yl]triphenylamine (TCTA), [5terphenyl-1,3-phenylene]bis[diphenylphosphine oxide] (POPH), 3,3',5,5'-tetra[(m-pyridyl)-phen-3-yl]biphenyl (BP4mPy) were purchased from Luminescence Technology Corp and poly(4styrenesulfonic acid) (PSSH) solution (18 wt $\%$ in $\mathrm{H}_{2} \mathrm{O}, M_{\mathrm{w}} \approx$ $75000 \mathrm{~g} \mathrm{~mol}^{-1}$ ) was purchased from Sigma Aldrich. The synthesis of $\operatorname{Ir}(\mathrm{DTri})_{3}$ has been previously reported. ${ }^{41}$

\section{Photophysical properties}

UV-vis and photoluminescence (PL) spectra of films on fused silica substrates were measured using Cary 5000 UV-Vis-NIR and Jobin-Yvon Horiba Fluoromax 4 spectrometers, respectively. Films were prepared by spin-coating the mixtures at a concentration of $20 \mathrm{mg} \mathrm{mL} \mathrm{mL}^{-1}$ in distilled and degassed dichloromethane at $2000 \mathrm{rpm}$ before annealing at $100{ }^{\circ} \mathrm{C}$ for $30 \mathrm{~min}$. Time-correlated single photon counting (TCSPC) measurements were undertaken using a Jobin-Yvon Florolog 3 spectrometer, with a pulsed LED (Horiba NanoLED). Photoluminescence quantum yields (PLQYs) were measured using an integrating sphere, coupled with an $\mathrm{He}-\mathrm{Cd}$ laser with $325 \mathrm{~nm}$ excitation and beam power of around $0.2 \mathrm{~mW}$. The measurements were undertaken with the sample held under a nitrogen atmosphere.

\section{Charge mobility}

Hole and electron mobilities were obtained using metal-insulator-semiconductor charge extraction by linearly increasing voltage (MIS-CELIV) ${ }^{42}$ and photo-MIS-CELIV methods, ${ }^{43}$ respectively. The device structure for hole mobility was ITO/cyclotene 3022-35 (BCB, Dow Chemical Company) (30 nm) $/ \mathrm{MgF}_{2}(50 \mathrm{~nm}) /$ emissive layer/MoOx $(8 \mathrm{~nm}) / \mathrm{Ag}(100 \mathrm{~nm})$ with the ITO connected to the function generator (Agilent 33250A from Aglient technologies Inc.). The device structure for the electron mobility measurements was ITO/BCB $(30 \mathrm{~nm}) / \mathrm{MgF}_{2}(50 \mathrm{~nm}) /$ emissive layer/Al $(100 \mathrm{~nm})$ with the ITO connected to the oscilloscope (Waverunner 6200A from LeCroy corporation).

The BCB solution in mesitylene (Sigma-Aldrich 98\%) was diluted 1:10 by volume with mesitylene, and the solution was spin-coated at $5000 \mathrm{rpm}$ in a glove box $\left(\mathrm{O}_{2}\right.$ and $\left.\mathrm{H}_{2} \mathrm{O}<0.1 \mathrm{ppm}\right)$ before annealing at $300{ }^{\circ} \mathrm{C}$ for $10 \mathrm{~min}$. The substrates were then transfer to a vacuum evaporation chamber (MBRAUN and $10^{-6} \mathrm{mbar}$ ) for deposition of $50 \mathrm{~nm} \mathrm{MgF}$. The emissive layers were spin-coated from $20 \mathrm{mg} \mathrm{mL} \mathrm{mL}^{-1}$ solutions in distilled degassed dichloromethane at $2000 \mathrm{rpm}$ and then annealed at $100{ }^{\circ} \mathrm{C}$ for $30 \mathrm{~min}$ to give films with a thickness of $\approx 150 \mathrm{~nm}$. Finally, the samples were transferred to the vacuum 
evaporation chamber for deposition of $100 \mathrm{~nm} \mathrm{Al}$ for the photoMIS-CELIV experiment or $8 \mathrm{~nm}$ MoOx and $100 \mathrm{~nm} \mathrm{Ag}$ for the MIS-CELIV measurement. A High Efficiency VIOLET LED emitter (LZ1-10UB00-01U7 purchased from OSRAM SYLVANIA Inc.) with 385-410 $\mathrm{nm}$ emission and $80 \mathrm{~mW}$ power was used for photoMIS-CELIV experiments. The mobility was calculated from the time for maximum current extraction using:

$$
\mu=\frac{2 d_{\mathrm{s}}^{2}}{\frac{\mathrm{d} u}{\mathrm{~d} t} t_{\max }{ }^{2}}\left(1+\frac{\varepsilon_{\mathrm{s}} d_{\mathrm{i}}}{\varepsilon_{\mathrm{i}} d_{\mathrm{s}}}\right)
$$

where $d_{\mathrm{i}}, \varepsilon_{\mathrm{i}}$ and $d_{\mathrm{s}}, \varepsilon_{\mathrm{s}}$ are insulator and semiconductor thicknesses and relative permittivities, respectively. $\mathrm{d} u / \mathrm{d} t$ is the slope of the linearly increased voltage and $t_{\max }$ is the time at maximum extraction current.

\section{XPS analysis}

XPS experiments were performed using a Kratos Axis Supra instrument (Kratos Analytical Ltd). Monochromatic Al K-alpha $(1486.6 \mathrm{eV})$ radiation was used as the excitation source. Spectra were collected in the hybrid lens mode, with an excitation power of $225 \mathrm{~W}$ and a pass energy of $160 \mathrm{eV}$. Depth profiling was performed using Ar1000+ clusters accelerated to a kinetic energy of $10 \mathrm{keV}$ rastered in a $3 \mathrm{~mm} \times 3 \mathrm{~mm}$ region. To minimize the effect of atmosphere and subsequent contamination, the sample was kept under a nitrogen atmosphere, except during transfer to the ultrahigh vacuum chamber of the spectrometer (less than 15 minutes). The Casa XPS software was used for spectral peak fitting.

\section{OLEDs fabrication}

$20 \Omega \square^{-1}$ patterned ITO $(1.5 \mathrm{~cm} \times 1.5 \mathrm{~cm})$ was purchased from Xinyan Technology Ltd and cleaned using ultrasonication for $15 \mathrm{~min}$ in each of Alconox, de-ionised water, acetone and 2-propanol. After drying under a nitrogen flow and treatment with UV-ozone for $20 \mathrm{~min}$, filtered PEDOT:PSS was spin-coated onto the ITO at $5000 \mathrm{rpm}$ before being annealed at $150{ }^{\circ} \mathrm{C}$ for $15 \mathrm{~min}$. The PEDOT:PSS layer was around $35 \mathrm{~nm}$ thick. The PSSH-modified PEDOT:PSS ( $m$-PEDOT:PSS) was prepared following the literature method. ${ }^{35}$ Briefly the aqueous poly(4styrenesulfonic acid) (PSSH) was diluted with de-ionised water in a $10 \%$ volume ratio and then mixed with the PEDOT:PSS solution in a $50 \%$ volume ratio. For deposition of the emissive layer or PVK, the $(m$-)PEDOT:PSS coated substrates were transferred to a glove box with $\mathrm{O}_{2}<0.3 \mathrm{ppm}$ and $\mathrm{H}_{2} \mathrm{O}<0.1 \mathrm{ppm}$. PVK (7.5 $\mathrm{mg} \mathrm{mL}^{-1}$ ) in distilled chloroform was spin-coated at $5000 \mathrm{rpm}$ onto the ( $\mathrm{m}$-)PEDOT:PSS layer and annealed at $120^{\circ} \mathrm{C}$ for $20 \mathrm{~min}$. The layer was then washed with chlorobenzene while being spun at $2500 \mathrm{rpm}$ to remove any loose particles from the surface before annealing for $10 \mathrm{~min}$ at $120{ }^{\circ} \mathrm{C}$. Emissive layers with a thickness of $\approx 55 \mathrm{~nm}$ were prepared by spin-coating the mixtures of the materials at a concentration of $10 \mathrm{mg} \mathrm{mL}^{-1}$ in distilled degassed dichloromethane at $3000 \mathrm{rpm}$ before annealing at $100{ }^{\circ} \mathrm{C}$ for $30 \mathrm{~min}$. The dichloromethane was dried over calcium hydride $\left(\mathrm{CaH}_{2}\right)$ under an argon atmosphere before distillation and it was deoxygenated with three cycles of freeze-pump-thaw, backfilling with argon. Finally, a $45 \mathrm{~nm}$ BP4mPy electron transport layer and $1 \mathrm{~nm}$ LiF and $100 \mathrm{~nm} \mathrm{Al}$ were deposited at rates of 1.0, 0.1 and $1.0 \AA \mathrm{s}^{-1}$, respectively in a thermal vacuum evaporation system (Kurt. J. Lesker SPECTROS evaporation system) with the initial pressure of $5 \times 10^{-7} \mathrm{mbar}$. The current density-voltageluminance $(J-V-L)$ characteristics were measured in a nitrogen filled glovebox using a Keithley 2400 source meter coupled with an absolute EQE measurement system with a calibrated integrating sphere (Hamamatsu Photonics C9920-12).

\section{Conflicts of interest}

There are no conflicts to declare.

\section{Acknowledgements}

The work was carried at the Centre for Organic Photonics \& Electronics at The University of Queensland. P. L. B. is an Australian Research Council Laureate Fellow (FL160100067) and the work was supported by the Fellowship. We would like to thank Associate Professor Lipton-Duffin of Central Analytical Research Facility, Queensland University of Technology, for the XPS measurements and assistance with their analysis.

\section{References}

1 P.-L. Zhong, C.-J. Zheng, M. Zhang, J.-W. Zhao, H.-Y. Yang, Z.-Y. He, H. Lin, S.-L. Tao and X.-H. Zhang, Org. Electron., 2020, 76, 105449.

2 J.-H. Lee, H. Shin, J.-M. Kim, K.-H. Kim and J.-J. Kim, ACS Appl. Mater. Interfaces, 2017, 9, 3277-3281.

3 S. Lee, K.-H. Kim, D. Limbach, Y.-S. Park and J.-J. Kim, $A d v$. Funct. Mater., 2013, 23, 4105-4110.

4 H. Lim, H. Shin, K.-H. Kim, S.-J. Yoo, J.-S. Huh and J.-J. Kim, ACS Appl. Mater. Interfaces, 2017, 9, 37883-37887.

5 Y. Seino, H. Sasabe, Y.-J. Pu and J. Kido, Adv. Mater., 2014, 26, 1612-1616.

6 M. Zhang, K. Wang, C.-J. Zheng, W. Liu, H. Lin, S.-L. Tao and X.-H. Zhang, Org. Electron., 2017, 50, 466-472.

7 Y.-T. Hung, Z.-Y. Chen, W.-Y. Hung, D.-G. Chen and K.-T. Wong, ACS Appl. Mater. Interfaces, 2018, 10, 34435-34442.

8 B. Zhao, T. Zhang, B. Chu, W. Li, Z. Su, H. Wu, X. Yan, F. Jin, Y. Gao and C. Liu, Sci. Rep., 2015, 5, 10697.

9 C.-Y. Huang, S.-Y. Ho, C.-H. Lai, C.-L. Ko, Y.-C. Wei, J.-A. Lin, D.-G. Chen, T.-Y. Ko, K.-T. Wong and Z. Zhang, J. Mater. Chem. C, 2020, 8, 5704-5714.

10 Y.-S. Park, S. Lee, K.-H. Kim, S.-Y. Kim, J.-H. Lee and J.-J. Kim, Adv. Funct. Mater., 2013, 23, 4914-4920.

11 P. L. dos Santos, F. B. Dias and A. P. Monkman, J. Phys. Chem. C, 2016, 120, 18259-18267.

12 B. Yao, X. Lin, B. Zhang, H. Wang, X. Liu and Z. Xie, J. Mater. Chem. C, 2018, 6, 4409-4417.

13 K. Sun, Y. Sun, W. Tian, D. Liu, Y. Feng, Y. Sun and W. Jiang, J. Mater. Chem. C, 2018, 6, 43-49. 
14 M. Jung, K. H. Lee, J. Y. Lee and T. Kim, Mater. Horiz., 2020, 7, 559-565.

15 Y.-X. Zhang, B. Wang, Y. Yuan, Y. Hu, Z.-Q. Jiang and L.-S. Liao, Adv. Opt. Mater., 2017, 5, 1700012.

16 X. Ban, K. Sun, Y. Sun, B. Huang, S. Ye, M. Yang and W. Jiang, ACS Appl. Mater. Interfaces, 2015, 7, 25129-25138.

17 X. Ban, K. Sun, Y. Sun, B. Huang and W. Jiang, Org. Electron., 2016, 33, 9-14.

18 X. Ban, K. Sun, Y. Sun, B. Huang and W. Jiang, ACS Appl. Mater. Interfaces, 2016, 8, 2010-2016.

19 Y. Feng, T. Lu, D. Liu, W. Jiang and Y. Sun, Org. Electron., 2019, 67, 136-140.

20 Q. Wang and H. Aziz, Adv. Opt. Mater., 2015, 3, 967-975.

21 L. Liu, B. Zhang, Z. Xie, J. Ding and L. Wang, Org. Electron., 2013, 14, 55-61.

22 L. Liu, X. Liu, K. Wu, J. Ding, B. Zhang, Z. Xie and L. Wang, Org. Electron., 2014, 15, 1401-1406.

23 Y. You, S. H. Kim, H. K. Jung and S. Y. Park, Macromolecules, 2006, 39, 349-356.

24 S. C. Lo, N. A. H. Male, J. P. J. Markham, S. W. Magennis, P. L. Burn, O. V. Salata and I. D. W. Samuel, Adv. Mater., 2002, 14, 975-979.

25 C.-K. Moon, Molecular Orientation and Emission Characteristics of Ir Complexes and Exciplex in Organic Thin Films, Springer, 2019.

26 K.-H. Kim, C.-K. Moon, J. W. Sun, B. Sim and J.-J. Kim, Adv. Opt. Mater., 2015, 3, 895-899.

27 S. Wang, X. Wang, B. Yao, B. Zhang, J. Ding, Z. Xie and L. Wang, Sci. Rep., 2015, 5, 1-9.

28 X. Gong, J. C. Ostrowski, G. C. Bazan, D. Moses and A. J. Heeger, Appl. Phys. Lett., 2002, 81, 3711-3713.
29 F.-C. Chen, Y. Yang, M. E. Thompson and J. Kido, Appl. Phys. Lett., 2002, 80, 2308-2310.

30 B. Tong, Q. Mei, S. Wang, Y. Fang, Y. Meng and B. Wang, J. Mater. Chem., 2008, 18, 1636-1639.

31 S. Sanderson, B. Philippa, G. Vamvounis, P. L. Burn and R. D. White, J. Chem. Phys., 2019, 150, 094110.

32 M. Gao, T. Lee, P. L. Burn, A. E. Mark, A. Pivrikas and P. E. Shaw, Adv. Funct. Mater., 2020, 30, 1907942.

33 J. Saghaei, A. M. Brewer, W. Jiang, S. M. Russell, P. L. Burn and A. Pivrikas, Thin Solid Films, 2021, 718, 138475.

34 C. Murawski, K. Leo and M. C. Gather, Adv. Mater., 2013, 25, 6801-6827.

35 Y. Xiang, G. Xie, Q. Li, L. Xue, Q. Xu, J. Zhu, Y. Tang, S. Gong, X. Yin and C. Yang, ACS Appl. Mater. Interfaces, 2019, 11, 29105-29112.

36 K. F. Jeltsch, G. Lupa and R. T. Weitz, Org. Electron., 2015, 26, 365-370.

37 Y. Liu, X. Wei, Z. Li, J. Liu, R. Wang, X. Hu, P. Wang, Y. Yamada-Takamura, T. Qi and Y. Wang, ACS Appl. Energy Mater., 2018, 1, 543-551.

38 A. van Dijken, A. Perro, E. A. Meulenkamp and K. Brunner, Org. Electron., 2003, 4, 131-141.

39 J. Cameron and P. J. Skabara, Mater. Horiz., 2020, 7, 1759-1772.

40 S. Kwon, K.-R. Wee, C. Pac and S. O. Kang, Org. Electron., 2012, 13, 645-651.

41 L. G. von Reventlow, W. Jiang, D. M. Stoltzfus, S. M. Russell, P. L. Burn and A. Colsmann, Adv. Opt. Mater., 2020, 8, 2001289.

42 M. Gao, P. L. Burn and A. Pivrikas, J. Appl. Phys., 2019, 126, 035501.

43 M. Gao, P. L. Burn and A. Pivrikas, ACS Photonics, 2021, 8, 2425-2430. 